\title{
Discordance for ankylosing spondylitis in monozygotic twins
}

\author{
C. J. EASTMOND* AND J. C. WOODROW
}

From the Nuffield Unit of Medical Genetics, Department of Medicine, University of Liverpool, Ashton Street P.O. Box 147, Liverpool L69 3BX

SUMMARY Three monozygotic twin pairs, each over the age of 45 years, with ankylosing spondylity are described. In two pairs there is discordance for this disease and in the third pair there is a marked difference in the severity of this disease. These findings provide evidence that environmental factoos are necessary not only for the initial development of ankylosing spondylitis, but possibly also for determining its future severity.

Genetic factors are known to be important in the aetiology of the seronegative spondarthritides (Emery and Lawrence, 1967; Moll and Wright, 1973; Lawrence, 1974). The finding of an increased frequency of the histocompatibility antigen B27 in ankylosing spondylitis by Brewerton et al. (1973a) and Schlosstein et al. (1973) suggested that at least part of the genetic susceptibility to ankylosing spondylitis is due to genes in the HLA chromosomal region. Associations have also been found between HLA B27 and Reiter's syndrome (Brewerton et al., 1973b; Woodrow et al., 1974) and the reactive arthropathies (Aho et al., 1973). While genetic factors are known to be important in predisposing to Reiter's syndrome (Lawrence, 1974) and the reactive arthropathies, there is also evidence that infective micro-organisms are necessary for the initial development of these diseases. Similar direct evidence of an environmental factor being necessary for the development of ankylosing spondylitis is

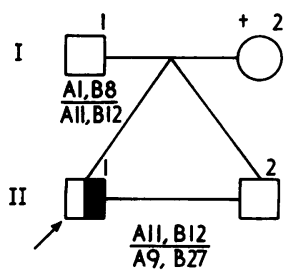

Fig. 1 Pedigree of family $P$ showing discordance for ankylosing spondylitis in monozygotic twins.
Accepted for publication November 20, 1977

* Present address: Department of Rheumatology \& Rehabilitation, School of Medicine, 36 Clarendon Road, Leeds LS2 9PJ

Correspondence to Dr. J. C. Woodrow lacking. Moesmann (1960), reviewing the publish data on monozygous twins and ankylosing spond $\overrightarrow{y 0}$ litis, found nine reported twin pairs of which three

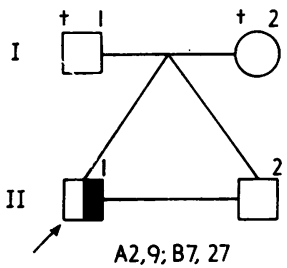

Fig. 2 Pedigree of fami $R$ showing discordance fog ankylosing spondylitis in $\vec{a}$ monozygotic twins.

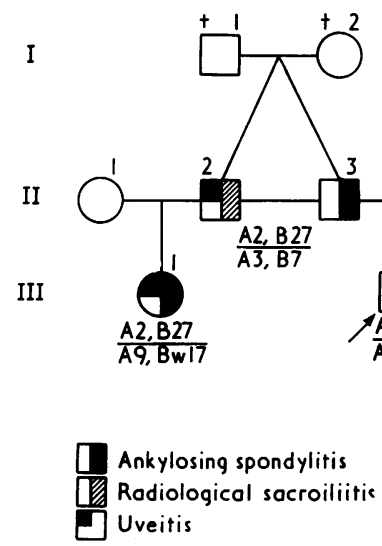

Fig. 3 Pedigree of family $E$ showing concordance for radiological sacroiliitis and discordance for clinical ankylosing spondylitis and anterior uveitis in monozygotic twins. 
were discordant for ankylosing spondylitis. Three further concordant pairs of monozygotic twins have since been reported (Kuthan and Navratil, 1966; Truog et al., 1975). We report our findings on three pairs of monozygotic twins seen during the course of family studies of ankylosing spondylitis.

\section{Patients and methods}

Each twin had a full history and rheumatological examination and radiographs of the sacroiliac joints were performed. Radiographs of the spine were taken where indicated. Blood samples were taken for multiple red blood cell grouping (ABO, Rhesus, MNS, P, Kell, Duffy, and Kidd) and HLA typing, which was performed by a microlymphocytotoxicity method (Teraski and McClelland, 1964). Other affected members of the twins' families were examined clinically and radiologically and blood taken for HLA typing.

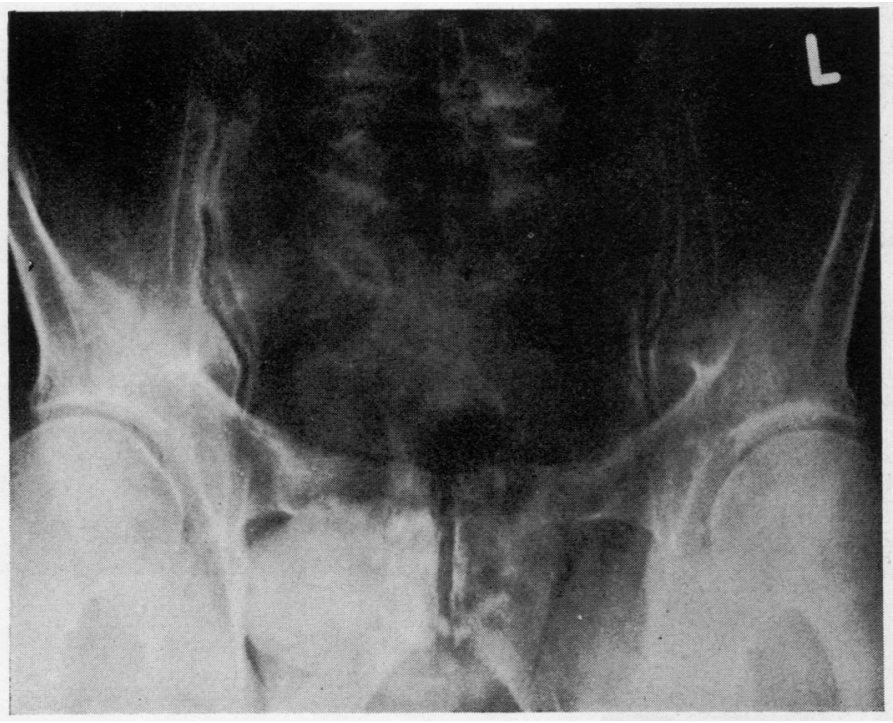

Fig. 4 Radiologically normal sacroiliac joints in unaffected twin (II. 2) of pair $P$.

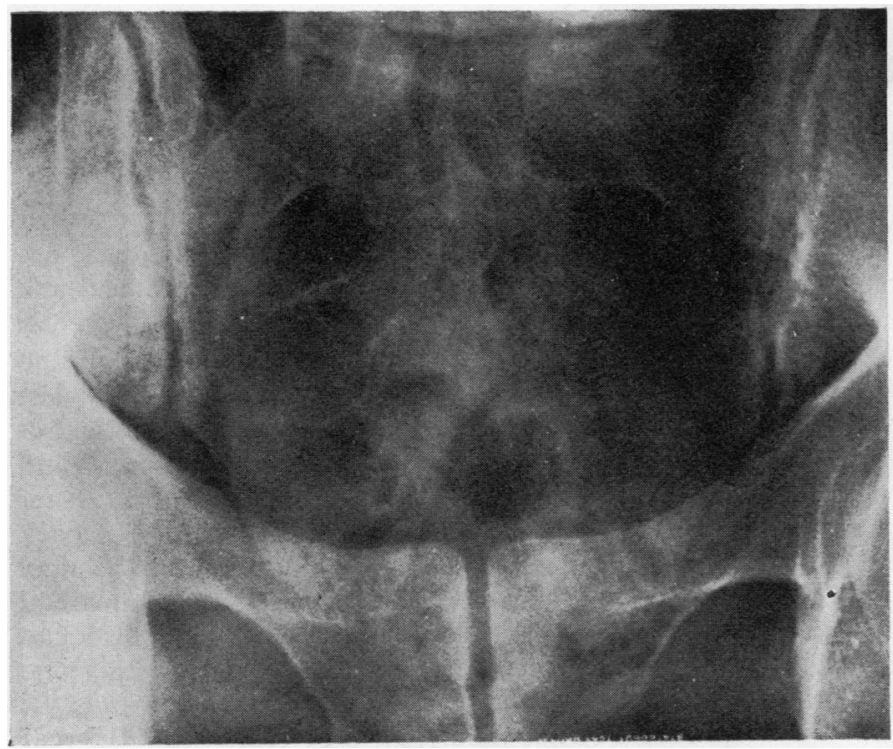

Fig. 5 Radiologically normal sacroiliac joints in unaffected twin (II. 2) of pair $R$. 


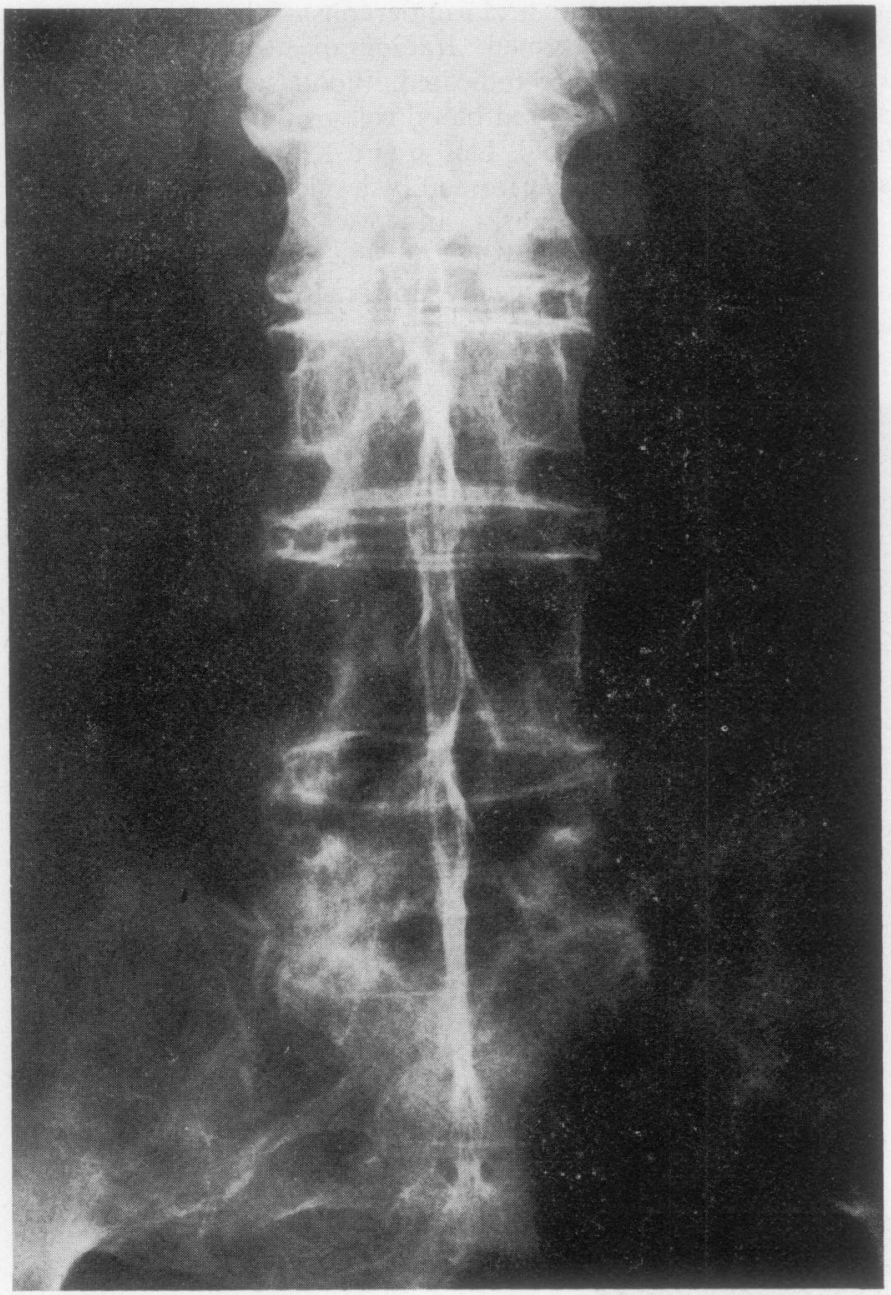

Fig. 6 Radiograph of lumbar spine and sacroiliac joints of the more severely affected twin (II. 3) of pair E, showing fusion of the sacroiliac joints and bamboo spine.

\section{Results}

The ages of the twin pairs E, P, and R were 59 years, 52 years, and 45 years respectively. The probabilities, based on red cell grouping, that they are monozygotic are $0.972,0.956$, and 0.976 respectively. The pedigrees of each pair of twins are shown in Figs. 1-3. In the pairs $P$ and $R$ (Figs. 1 and 2 respectively) the probands have ankylosing spondylitis but their identical twin brothers have no suggestive symptoms, normal spinal movements, and radiologically normal sacroiliac joints (Figs. 4, 5). Twins $P$ lived in the same household until the affected twin came to live in Liverpool at the age of 32 years, which was 9 years after the onset of his back symptoms. Twins $R$ both lived in the same household until 20 years ago.
With regard to the third twin pair (twins E; Fig. both lived in the same household up to their twenties. Both have radiological sacroiliitis (Figs 6 , 7), but one (II.3, Fig. 3) has severe clinical and radiological ankylosing spondylitis (Fig. 6), wheres his twin (II.2, Fig. 3) has no back symptoms and nig clinical or radiological spondylitis (Fig. 7). This les severely affected twin has had anterior uveitis, but his more severely affected twin brother has not. Both twins have affected children. Twin II.2 has a 33-yeer old daughter (III.1) with a 15-year history of back pain and stiffness, some limitation of all spinal movements, a chest expansion of $4 \mathrm{~cm}$, and unilatera grade 3 radiological sacroiliitis. She has also hat recurrent anterior uveitis since the age of 27 yearo The other twin (II.3) has a son (III.2), who was the proband of this family, aged 33 years with a 15-ye 


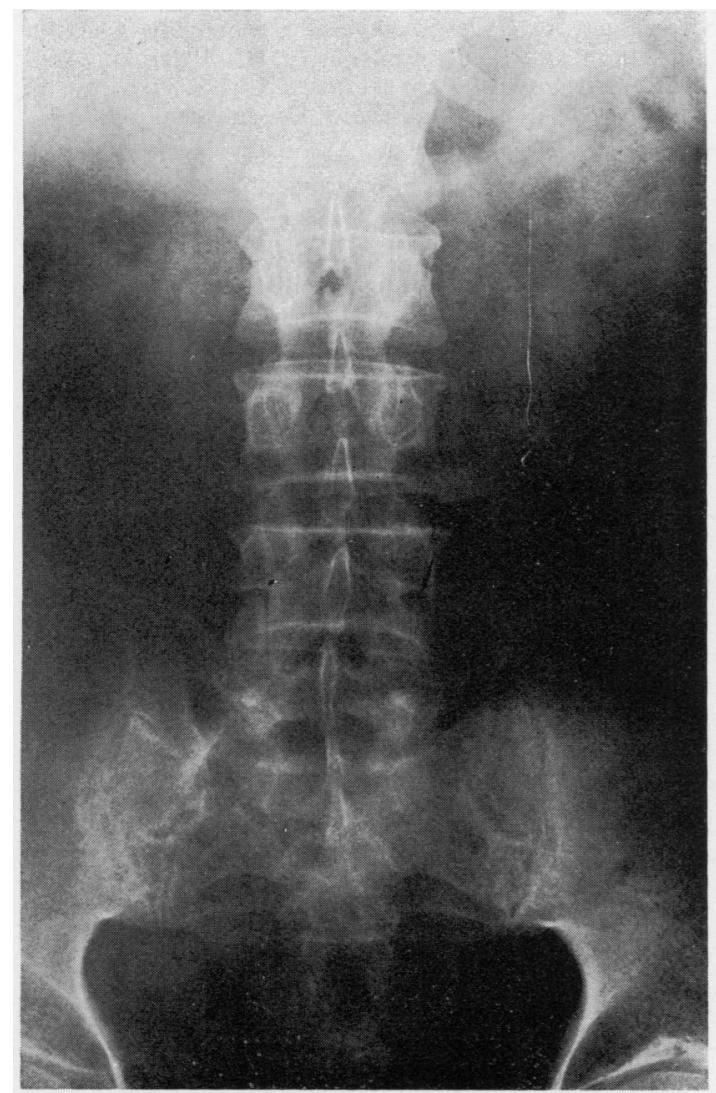

Fig. 7 Radiograph of lumbar spine and sacroiliac joints of the less severely affected twin (II. 2) of pair E, showing bilateral grade 3 sacroiliitis without spondylitis.

history of back pain and stiffness with marked limitation of all spinal movements, a chest expansion of $3 \mathrm{~cm}$, and radiological sacroiliitis and spondylitis but has not had anterior uveitis.

\section{Discussion}

The twin pairs $\mathbf{P}$ and $\mathrm{R}$ confirm that discordance for ankylosing spondylitis does occur in monozygotic twins. Since both pairs are over the age of 45 years and it is unusual for symptoms or signs of ankylosing spondylitis to appear after that age there is only a remote possibility of the unaffected twins developing this disease in the future. One of Moesmann's (1960) discordant monozygotic twin pairs was aged 47 years but the ages of the other two discordant pairs were not known. Persisting discordance for ankylosing spondylitis in monozygotic twins is strong evidence in favour of an environmental factor having a role in the pathogenesis of this disease.

The twin pair $\mathrm{E}$ is of considerable interest since although both twins have radiological sacroiliitis the severity and extent of their disease as judged both clinically and radiologically are very different. It is possible to explain this disparity by suggesting that the lesser affected twin has ankylosing spondylitis of recent onset, but this would imply an age of onset considerably older than is considered typical. An alternative explanation is that different environmental factors, or a quantitative difference of the same environmental factor has resulted in a difference of severity of disease in these two individuals with identical genetic susceptibility.

Uveitis may occur at any age but it is notable that there is also discordance for this disease. It has been shown (Brewerton et al., 1973c; Woodrow et al., 1975) that HLA B27 predisposes to anterior uveitis and the discordance in these HLA B27-positive twins again implies the role of chance environmental factors in this disease.

The findings in these monozygotic twins suggest that while genetic factors are important in the pathogenesis of ankylosing spondylitis environmental factors are necessary in determining not only the initial development of the disease but possibly its future severity as well.

We are most grateful to the National Tissue Typing Reference Laboratory, Bristol, and to the Transplantation and Immunology Branch, National Institutes of Health, Bethesda, Maryland, for supplying typing sera. Mr. N. Usher and others provided excellent technical assistance. C.J.E. received financial support from the Medical Research Committee of the Mersey Regional Health Authority.

\section{References}

Aho, K., Ahvonen, P., Lassus, A., Sievers, K., and Tiilikainen, A. (1973). HL-A antigen 27 and reactive arthritis. Lancet, 2, 157.

Brewerton, D. A., Caffrey, M., Hart, F. D., James, D. C. O. Nicholls, A., and Sturrock, R. D. (1973a). Ankylosing spondylitis and HL-A 27. Lancet, 1, 904-907.

Brewerton, D. A., Caffrey, A., Nicholls, A., Walters, D., Oates, J. K., and James, D. C. O. (1973b). Reiter's disease and HL-A 27. Lancet, 2, 996-998.

Brewerton, D. A., Caffrey, M., Nicholls, A., Walters, D., and James, D. C. O. (1973c). Acute anterior uveitis and HL-A 27. Lancet, 2, 994-996.

Emery, A. E. H., and Lawrence, J. S. (1967). Genetics of ankylosing spondylitis. Journal of Medical Genetics, 4, 239-244.

Kuthan, F., and Navratil, J. (1966). Spondylarthrite ankylosante chez deux paires de jumeaux homozygotes. Revue du Rhumatisme et des Maladies Ostéoarticulaires, 33, 211-214.

Lawrence, J. S. (1974). Family survey of Reiter's disease. British Journal of Venereal Diseases, 50, 140-145.

Moesmann, A. (1960). Hereditary and exogenous etiological factors in ankylosing spondylitis. Acta Rheumatologica Scandinavica, 6, 144-150. 
Moll, J. M. H., and Wright, V. (1973). Familial occurrence of psoriatic athritis. Annals of the Rheumatic Diseases, 32, 181-201.

Schlosstein, L., Terasaki, P. I., Bluestone, R., and Pearson, C. M. (1973). High association of an HL-A antigen, W27, with ankylosing spondylitis. New England Journal of Medicine, 288, 704-706.

Terasaki, P. I., and McClelland, J. D. (1964). Microdroplet assay of human serum cytotoxins. Nature, 204, 998-1000.

Truog, P., Steiger, V., Contu, L., Galfre, G., Trucco, M., Bernoco, D., Bernoco, M., Birgen, I., Dolivo, P., and
Ceppellini, R. (1975). Ankylosing spondylitis (AS): ? population and family study using HL-A serology arfa MLR. Histocompatibility Testing, p. 788. Ed. by Kissmeyer-Nielson. Munksgaard, Copenhagen.

Woodrow, J. C., Treanor, B., and Usher, N. (1974). Th HL-A system in Reiter's syndrome. Tissue Antigens, 533-540.

Woodrow, J. C., Mapstone, R., Anderson, J., and Usher, (1975). HL-A 27 and anterior uveitis. Tissue Antigens, 116-120. 